\title{
Novel mode of action of c-kit tyrosine kinase inhibitors leading to NK cell-dependent antitumor effects
}

\author{
Christophe Borg, ${ }^{1}$ Magali Terme, ${ }^{1}$ Julien Taïeb, ${ }^{1}$ Cédric Ménard, ${ }^{1}$ Caroline Flament, ${ }^{1}$ \\ Caroline Robert, ${ }^{1}$ Koji Maruyama, ${ }^{1,2}$ Hiro Wakasugi, ${ }^{2}$ Eric Angevin, ${ }^{1}$ Kris Thielemans, ${ }^{3}$ \\ Axel Le Cesne, ${ }^{4}$ Véronique Chung-Scott, ${ }^{1}$ Vladimir Lazar, ${ }^{1}$ Isabelle Tchou, ${ }^{1}$ Florent Crépineau, ${ }^{1}$ \\ François Lemoine, ${ }^{5}$ Jacky Bernard, ${ }^{6}$ Jonhantan A. Fletcher, ${ }^{7}$ Ali Turhan, ${ }^{8}$ Jean-Yves Blay, ${ }^{9}$ \\ Alain Spatz, ${ }^{10}$ Jean-François Emile, ${ }^{11}$ Michael C. Heinrich, ${ }^{12}$ Salah Mécheri, ${ }^{13}$ \\ Thomas Tursz, ${ }^{1}$ and Laurence Zitvogel ${ }^{1}$
}

1Department of Clinical Biology, Equipe de Recherche Mixte 0208, INSERM, Institut Gustave Roussy, Villejuif, France. ${ }^{2}$ Pharmacology and Immunology Unit, National Cancer Center, Tokyo, Japan. ${ }^{3}$ Laboratory of Molecular and Cellular Therapy, Medical School of the Vrije Universiteit Brussel, Brussels, Belgium.

${ }^{4}$ Department of Medical Oncology, Institut Gustave Roussy, Villejuif, France. ${ }^{5}$ Centre d'Etudes et de Recherches en Virologie et Immunologie, Hôpitaux Pitié Salpétrière, Paris, France. ${ }^{6}$ Centre Jean Godinot, Reims, France. ${ }^{7}$ Harvard Medical School, Boston, Massachusetts, USA. ${ }^{8}$ Translational Research Unit, Institut Gustave Roussy, Villejuif, France. ${ }^{9 H}$ ospices Civils de Lyon, Hôpital Edouard Hériot, Lyon, France.

${ }^{10}$ Department of Pathology and Translational Research, Institut Gustave Roussy, Villejuif, France. ${ }^{11}$ Department of Pathology, Paul Brousse Hospital, Assistance Publique - Hôpitaux de Paris, Villejuif, France. ${ }^{12}$ Oregon Health and Science University Cancer Institute, Portland, Oregon, USA. 13Immuno-Allergy Unit, Pasteur Institute, Paris, France.

\begin{abstract}
Mutant isoforms of the KIT or PDGF receptors expressed by gastrointestinal stromal tumors (GISTs) are considered the therapeutic targets for STI571 (imatinib mesylate; Gleevec), a specific inhibitor of these tyrosine kinase receptors. Case reports of clinical efficacy of Gleevec in GISTs lacking the typical receptor mutations prompted a search for an alternate mode of action. Here we show that Gleevec can act on host DCs to promote NK cell activation. DC-mediated NK cell activation was triggered in vitro and in vivo by treatment of DCs with Gleevec as well as by a loss-of-function mutation of KIT. Therefore, tumors that are refractory to the antiproliferative effects of Gleevec in vitro responded to Gleevec in vivo in an NK cell-dependent manner. Longitudinal studies of Gleevec-treated GIST patients revealed a therapy-induced increase in IFN- $\gamma$ production by NK cells, correlating with an enhanced antitumor response. These data point to a novel mode of antitumor action for Gleevec.
\end{abstract}

\section{Introduction}

Gastrointestinal stromal tumors (GISTs) are the most common mesenchymal neoplasms of the gastrointestinal tract. Somatic gain-of-function mutations of the c-kit protooncogene are found in $85 \%$ of GISTs (1), and recently, mutations of the PDGFR $\alpha$ chain were reported in $35 \%$ of the GISTs lacking the KIT mutations (2). The 2-phenylaminopyrimidine compound imatinib mesylate (STI571; Gleevec) was initially designed to specifically block the ATP-binding site of break point cluster region/Abelson leukemia virus (BCR/ABL) tyrosine kinase, and it also inhibits the kinase activity of 3 related kinases: BCR/ABL, PDGFR, and KIT (3-5). Gleevec administration results in objective (partial or complete) response or stabilization in about $80 \%$ of GIST patients (6). Clinical response to Gleevec correlates with the mutational status of the c-kit gene. GISTs harboring an exon 11 mutation $(76 \%$ of GISTs) exhibit the highest objective response rate and the longest time to progression (7).

Nonstandard abbreviations used: bi-injection daily (bid); bone marrow-derived $\mathrm{DC}$ (BM-DC); break point cluster region/Abelson leukemia virus (BCR/ABL); chronic myelogenous leukemia (CML); c-kit loss-of-function mutation (W/Wv); fms-like tyrosine 3 kinase ligand (FL); gastrointestinal stromal tumor (GIST); progression-free survival (PFS); stem cell factor (SCF); transporter associated with antigen processing (TAP)

Conflict of interest: The authors have declared that no conflict of interest exists.

Citation for this article: J. Clin. Invest. 114:379-388 (2004)

doi:10.1172/JCI200421102.
However, several lines of evidence indicate that Gleevec might mediate antitumor effects by an alternate mode of action instead of having a direct effect on tumoral c-kit mutations. Indeed, the pharmacokinetics of Gleevec have no predictive value for clinical responses, and some GISTs with very low expression of KIT have been shown to respond to Gleevec $(8,9)$. We therefore hypothesized that, in addition to its cell-autonomous antitumor effects, Gleevec might act indirectly on host cells outside of the tumor. The validity of this hypothesis relied on case reports of GISTs devoid of mutations that we isolated in the cohort of patients responding to Gleevec. To demonstrate this novel mode of action of Gleevec, we selected mouse tumor models that were resistant to the antiproliferative effects of Gleevec in vitro but responded in vivo to long-term exposure to Gleevec or to short-term exposure to Gleevec combined with a DC growth factor, fms-like tyrosine 3 kinase ligand (FL) (10). Here we show that Gleevec acts on host DCs to promote NK cell activation and NK cell-dependent antitumor effects in mice. We also report that most GIST-bearing patients that were treated with Gleevec acquired NK cell activation, which positively correlated with clinical outcome (time to progression). This novel mode of action of Gleevec opens new fields of investigation for immunotherapeutic approaches.

\section{Results}

GISTs devoid of c-kit/PDGFR mutations respond to Gleevec. According to Heinrich and colleagues (7), the mutational status of c-kit predicts 
the clinical response of the GIST to Gleevec; they report objective (partial or complete) responses only in cases involving a mutation in the genes encoding c-kit or the PDGFR $\alpha$ chain. In this previous study (7), activating mutations of c-kit or PDGFR $\alpha$ were found in $88 \%$ and $5 \%$ of GISTs, respectively. In patients with GISTs harboring the exon $11 \mathrm{c}-\mathrm{kit}$ mutation, the partial response rate was $83 \%$, whereas patients with GISTs harboring the exon 9 c-kit mutation and those with no detectable mutation of c-kit or PDGFR $\alpha$ had a partial response rate of $48 \%$ and $0 \%$, respectively (7). However, here we report the first 6 cases ( 3 in a phase I/II French study and 3 in a phase II US study [ref. 7]) of GISTs that did not display the target mutations of Gleevec but still exhibited objective tumor responses. We analyzed the genomic DNA in these 6 paraffin-embedded primary GISTs and did not find any mutations in the following Gleevec targets: c-kit exons 9, 11, 13, and 17, and PDGFR $\alpha$ exons 12,14 , and 18 . However, 2 patients presenting with liver, stomach, or lung metastases did exhibit complete responses to Gleevec with 26 months of disease-free survival. One patient presenting with liver metastases displayed a partial response with 24 months of progression-free survival (PFS), and 3 patients exhibited stable disease (7, 15, and 17 months of PFS) (see Supplemental Table 1A; supplemental material available at http://www.jci.org/cgi/content/ full/114/3/379/DC1). This finding prompted the search for an alternate mode of action of Gleevec that is not cell autonomous.

In vivo efficacy of Gleevec in tumors resistant to Gleevec in vitro. Accordingly, we identified several mouse tumor models resistant to the antiproliferative effects of Gleevec in vitro (Figure 1A) but sensitive to Gleevec in vivo. While B16F10 melanoma cell proliferation was not inhibited by micromolar concentrations of Gleevec in vitro, the establishment of B16 lung metastases in C57BL/6 mice was significantly hampered by oral feeding with Gleevec (Figure 1B). Gleevec also induced significant antitumor effects against the AK7 mesothelioma and the MCA102 fibrosarcoma models (data not shown). The Gleevec-mediated antitumor effects could be potentiated by the adjunction of FL, a hematopoietic growth factor endowed with immunostimulatory capacities (10). Indeed, a short administration of Gleevec (4 days) combined with FL (FL+Gleevec) promoted synergistic antitumor effects against established AK7 mesothelioma with up to $45 \%$ tumor-free mice using FL+Gleevec versus $14 \%$ using FL alone or $0 \%$ using Gleevec alone (Figure 1C). Similarly, the combination of FL and Gleevec prevented 100\% of mice from developing the transporter associated with antigen processing-deficient (TAP-deficient) RMA-S lymphoma, whereas neither FL nor Gleevec alone prevented this lymphoma (Figure 2A). It is noteworthy that tumor-free mice were not immune to autologous tumor cells, since rechallenge was lethal in most cases (data not shown). Therefore, Gleevec alone or in combination with FL significantly curtails tumor progression in tumor models resistant to Gleevec in vitro, which suggests a non-cell autonomous mode of action.

Gleevec promotes NK cell-dependent antitumor effects. The combination of FL and Gleevec was unable to protect mice against the development of TAP-sufficient RMA tumors (Figure 2B). Since TAP-deficient tumor cells are known to be elective NK cell targets (11), and since immunosurveillance against AK7 and B16 involved NK cells $(10,12)$, we hypothesized that NK cells could be the critical effectors of the Gleevec-mediated antitumor effects. Indeed, the neutralization of $\mathrm{NK} 1.1^{+}$cells in $\mathrm{C} 57 \mathrm{BL} / 6$ mice inoculated with B16F10 melanoma cells abrogated the Gleevec-mediated antimetastatic effects (Figure 2C). Similar results were achieved in the RMA-S tumor model, in which anti-NK1.1 monoclonal anti- bodies significantly hampered the antitumor effects induced by the combination of FL and Gleevec (data not shown).

To confirm that long-term exposure to Gleevec or short-term administration of Gleevec in combination with FL promoted NK cell activation, we examined the upregulation of the activation marker CD69 on NK cells in various mouse strains (that is, in athymic Swiss ${ }^{n u / n u}$ and in immunocompetent C57BL/6 mice). Prolonged (15-21 days) oral feeding with Gleevec-induced loss of splenic T cells (Figure 3A) but selectively allowed NK cell survival and/or expansion and activation (Figure 3, B and C). In contrast, shorter exposure (4 days) to Gleevec did not promote NK
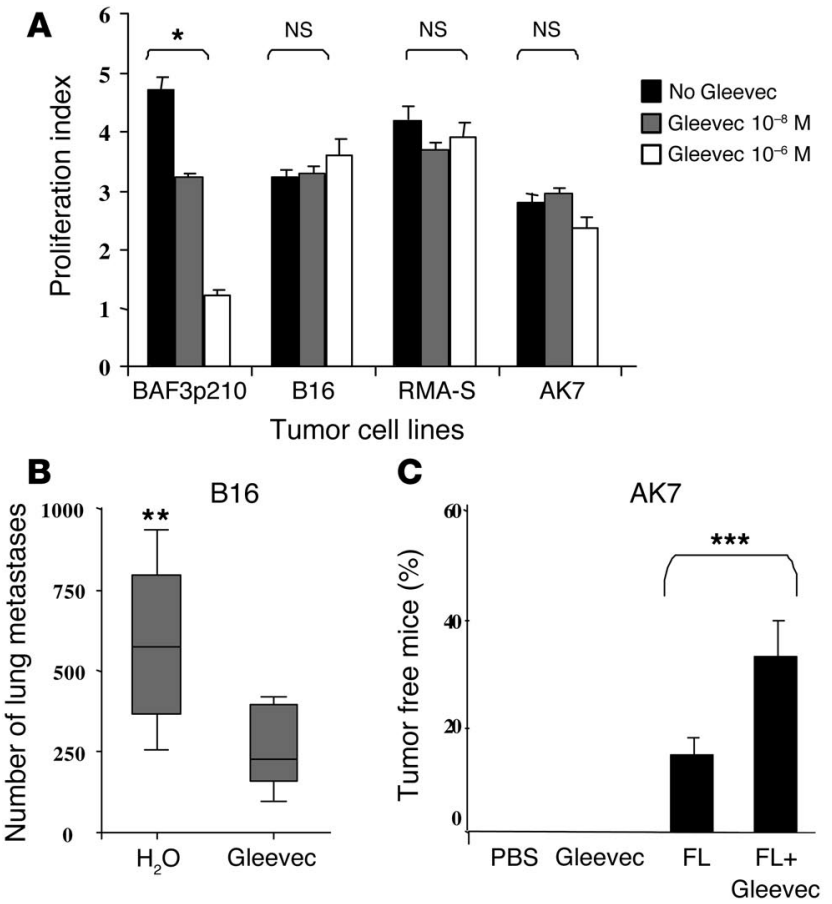

Figure 1

Gleevec prevented tumor progression in vivo in tumor models resistant to the Gleevec antiproliferative effects in vitro. (A) Mouse tumor models resistant to Gleevec in vitro. AK7, B16F10 (B16), RMA-S, MCA 102, or BAF3p210 cells (bearing the BCR/ABL translocation) were incubated for 24 hours with the indicated doses of Gleevec, and the absolute number of surviving cells was determined by trypan blue exclusion assay. Proliferation indexes are shown. The Wilcoxon twosample rank sum test was used to compare the proliferation indexes $\left({ }^{\star} P<0.05\right)$. (B) Gleevec prevents establishment of B16F10 lung metastases. We injected $5 \times 10^{5} \mathrm{~B} 16 \mathrm{~F} 10$ tumor cells in the tail vein at day 0 . Oral feeding with Gleevec $\left(150 \mathrm{mg} / \mathrm{kg}\right.$ bid) or $\mathrm{H}_{2} \mathrm{O}(200 \mu \mathrm{l})$ was administered on days 5-11 and mice were sacrificed for the enumeration of lung metastases on day 11. The data from 3 independent experiments, each including 5-7 mice per group, were pooled and are depicted. The Wilcoxon two-sample rank sum test was used to compare the number of lung metastases $\left({ }^{*} P<0.05\right.$, Gleevec versus $\mathrm{H}_{2} \mathrm{O}$ ). (C) FL and Gleevec synergize to eradicate AK7. We inoculated $3 \times 10^{6} \mathrm{AK} 7$ tumor cells in the abdominal flank of C57BL/6 mice on day 0 . FL was started at day 11 when AK7 tumors reached a diameter of $20 \pm 20 \mathrm{~mm}^{2}$. FL was continued for 10 days and combined with Gleevec the day before FL arrest and for 8 consecutive days (same doses as in B). Each experiment included 5-7 mice/group and was repeated twice with similar results. The Kruskal Wallis multiple comparison test was used for statistical analyses and significant effects are signified by triple asterisks. 

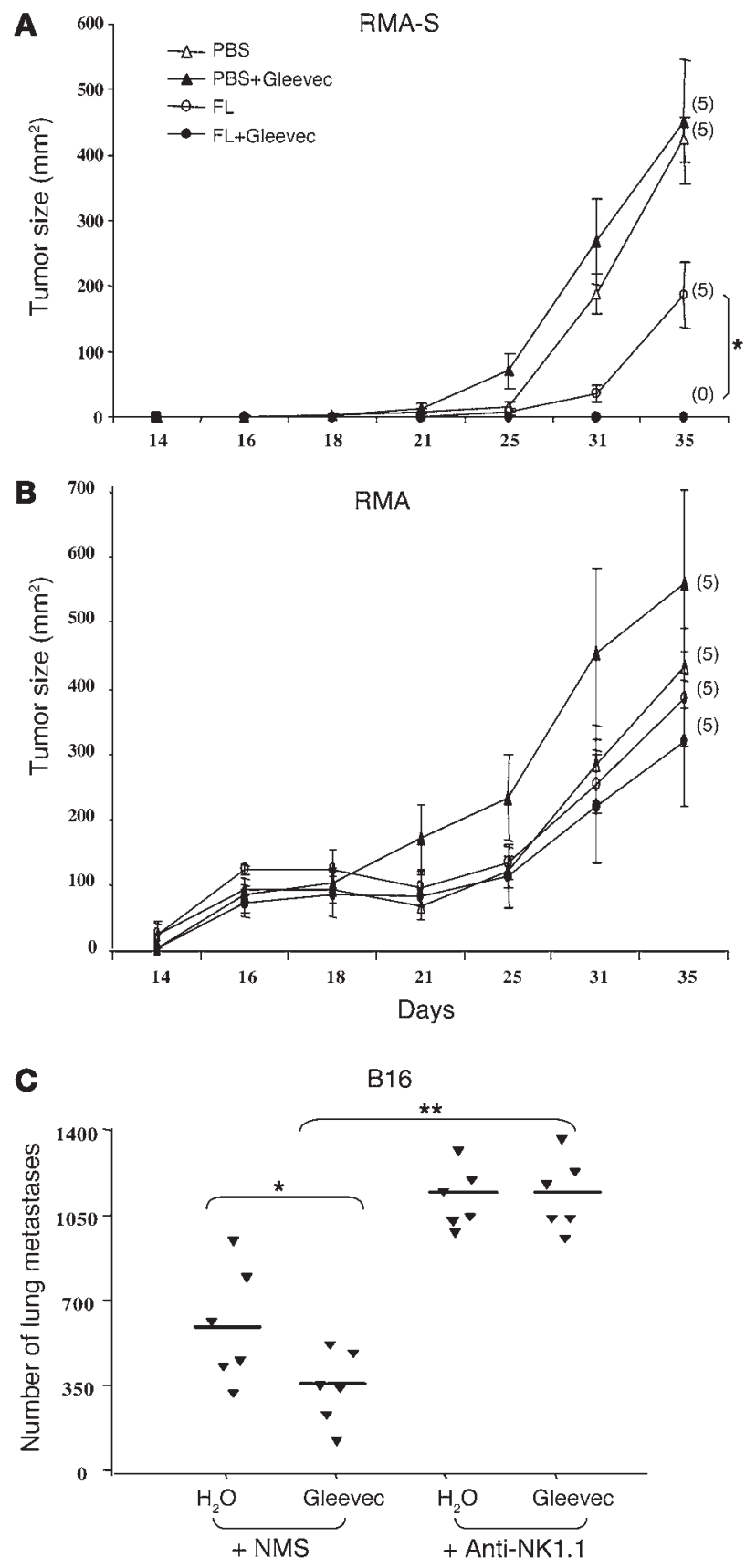

cell activation. However, the combination of FL with low dosages of Gleevec (FL+Gleevec for 4 days) activated NK cells, supporting the antitumor effects observed (Figure 1). Indeed, the number of $\mathrm{CD}^{-} / \mathrm{DX}^{+} / \mathrm{CD} 9^{+} \mathrm{NK}$ cells in the spleen (Figure 3D) and in the liver (see Supplemental Figure 1, A and B) of Swiss ${ }^{n u / n u}$ mice treated with $\mathrm{FL}+$ Gleevec was augmented compared with that in littermates receiving either agent alone, reaching a level comparable to that obtained after injection of recombinant interleukin-2. Moreover, only NK cells harvested from FL+Gleevec-treated or IL-2-treated mice secreted IFN- $\gamma$ following ex vivo stimulation (data not shown). The synergy of FL+Gleevec triggered NK cell activation in the C57BL/6 genetic background (Figure $3 \mathrm{E}$ ). We therefore conclude that NK cells are the critical effectors involved in the non-tumor-cell-autonomous mode of action of Gleevec.

\section{Figure 2}

Gleevec promoted NK cell-dependent antitumor effects. (A and B) FL and Gleevec synergize to prevent RMA-S tumor establishment. In one abdominal flank of C57BL/6 mice, TAP-deficient RMA-S cells were injected $(\mathbf{A})$, whereas TAP-sufficient RMA cells were injected into the other flank of the same mice (B). The same number of cells of each type were injected $\left(10^{6}\right.$ cells). From 6 days before injection (day -6$)$ to day 3 , FL $(10 \mu \mathrm{g} /$ day $)$ or PBS $(200 \mu \mathrm{l})$ was injected intraperitoneally. From day 1 to day 4 , Gleevec $\left(150 \mathrm{mg} / \mathrm{kg}\right.$ bid) or $\mathrm{H}_{2} \mathrm{O}(200 \mu \mathrm{l})$ was administered orally. The number of tumor-free mice at the end of the experiment is indicated in parentheses. Each experiment included 5 mice per group and was repeated twice with similar results. (C) The antitumor effects of Gleevec against B16F10 lung metastases are mediated by NK cells. Neutralizing anti-NK1.1 mAb (300 $\mu \mathrm{g}$ of PK136 $\mathrm{mAb} /$ mouse) or normal mouse serum (NMS) were administered intraperitoneally at days $-4,-2,0$, and 4 in C57BL/6 mice. At day 0 , $5 \times 10^{5} \mathrm{~B} 16 \mathrm{~F} 10$ tumor cells were inoculated into the tail vein. Oral feeding with Gleevec (150 mg/kg bid) or $\mathrm{H}_{2} \mathrm{O}(200 \mu \mathrm{l})$ was administered on days $5-11$, and mice were sacrificed for the enumeration of lung metastases at day 11. The results of one representative experiment (of 2) including 5-7 mice per group are shown. The Kruskal Wallis multiple comparison test was used to compare the number of lung metastases ( ${ }^{\star} P<0.05$ between Gleevec and $\mathrm{H}_{2} \mathrm{O}$ in NMS groups; ${ }^{* \star} P<0.01$ between NMS and anti-NK1.1 mAb in Gleevec groups; there was no significant difference between $\mathrm{H}_{2} \mathrm{O}$ and Gleevec in antiNK1.1 mAb groups).

Gleevec acts on host DCs to promote NK cell activation. Since a subset of mature NK cells expresses KIT and exhibits higher cytotoxic activity than the $\mathrm{KIT}^{-} \mathrm{NK}$ cell subpopulation (13), we investigated the direct effect of Gleevec on NK cells. In vivo treatment with $\mathrm{FL}+\mathrm{Gleevec}$ did not augment the frequency of $\mathrm{KIT}^{+} \mathrm{NK}$ cells $(7 \% \pm 2 \%$ of total NK cells in FL+Gleevec versus $7.2 \% \pm 2.6 \%$ in controls). Furthermore, Gleevec could not directly boost IFN- $\gamma$ production by bulk NK cells in vitro (Figure 4A). Since FL is known to amplify DCs, (14) and since mature DCs have the unique capacity to promote NK cell effector functions including IFN- $\gamma$ secretion and antitumor effects in vivo $(10,15)$, we hypothesized that Gleevec could confer an NK cell stimulatory capacity to host DCs. Gleevec enhanced IFN- $\gamma$ production by NK cells, but only when NK cells were cocultured with mouse bone marrow-derived DCs (BM-DCs) (Figure 4A) or spleenderived DCs (data not shown) stimulated with $10 \mathrm{nM}$ to $1 \mu \mathrm{M}$ of Gleevec for 20 hours. In untreated controls, one BM-DC triggered only 2 NK cells, whereas one Gleevec-pretreated BM-DC (BM-DC ${ }^{\text {STI })}$ efficiently triggered 10 NK cells (Figure 4B). Tyrphostin AG957, a nonselective tyrosine kinase inhibitor (16), did not promote DCmediated NK cell activation (Figure 4B). Adoptive transfer of BM$\mathrm{DC}^{\mathrm{STI}}$ into Swiss ${ }^{n u / n u}$ mice led to NK cell activation, as indicated by the upregulation of CD 69 on splenic DX5 ${ }^{+} / \mathrm{CD}^{-} \mathrm{NK}$ cells (data not shown). IL-2, IL-12, and IL-18 were not detectable in the supernatants of BM-DCs cultured alone or cocultured with NK cells, whether stimulated with Gleevec or not. Since Gleevec-mediated NK cell activation was also observed in IL-12 p35/- BM-DCs, we ruled out a role for IL-12 (Figure 4C). The levels of thymus and activation-regulated chemokine (TARC), macrophage-derived chemokine (MDC), and fractalkine were similar in BM-DCs and Gleevec-treated BM-DCs, whether they were cultured alone or cocultured with NK cells (data not shown). We confirmed that the NK cell stimulatory activity was not contained in the supernatants of Gleevec-stimulated BM-DCs, but rather was associated with the DC membrane since separation of Gleevec-pretreated BM-DCs from NK cells significantly hampered NK cell activation by DCs (Figure 4D). 
A
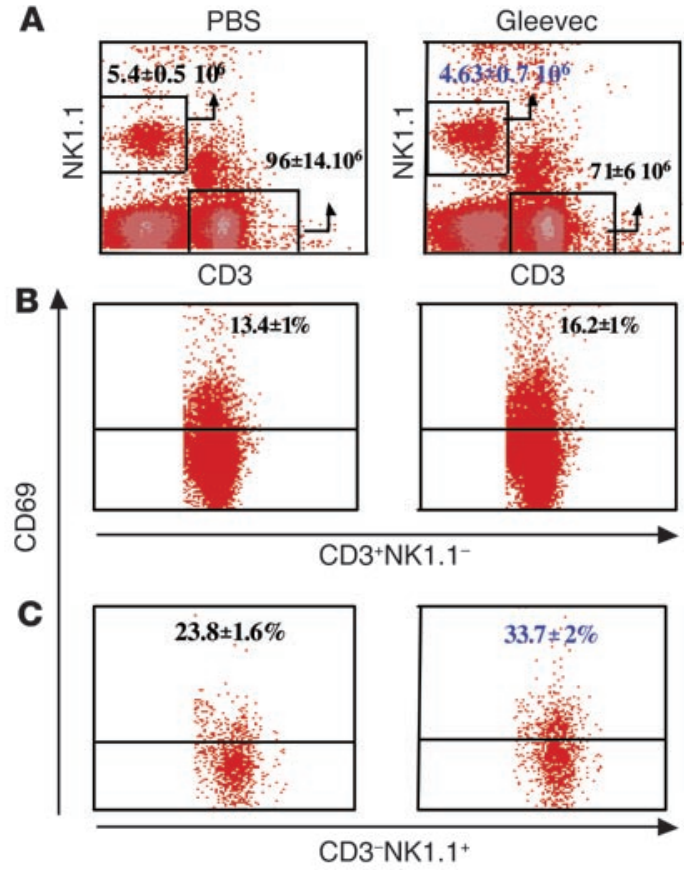

Gleevec

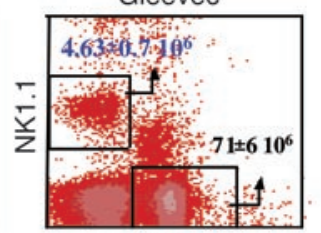

CD3
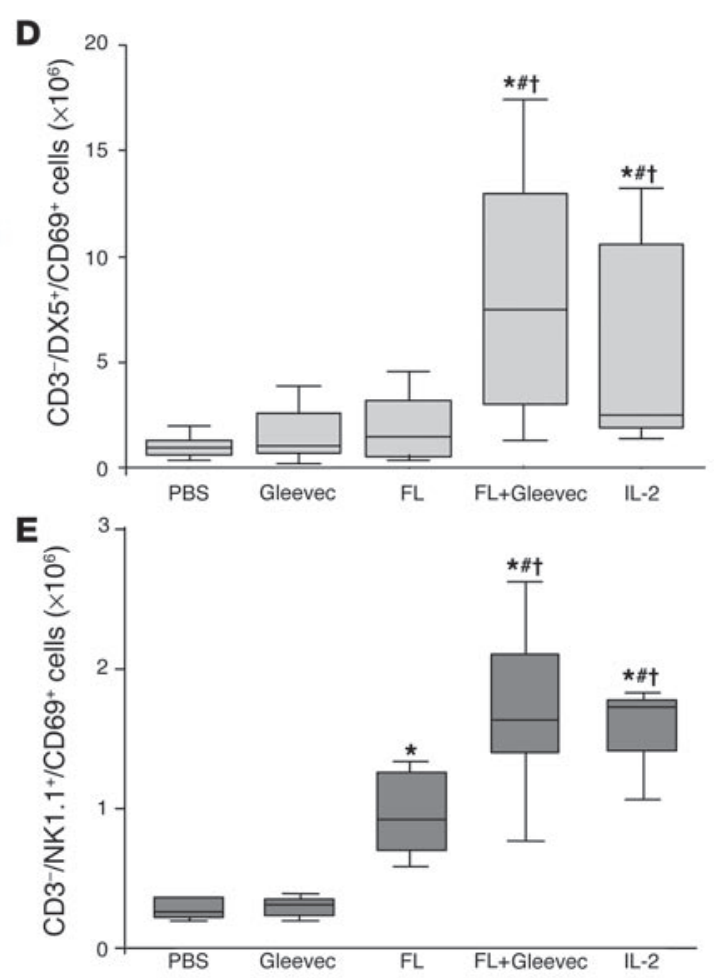

Figure 3

Gleevec alone or combined with FL induced NK cell activation in vivo. (A) Long-term exposure to Gleevec in C57BL/6 mice induced reduction of the splenic T lymphocyte counts but selectively maintained the NK cell subset. After red blood cell removal and an adherence step, splenocytes were enumerated after 15-21 days of oral feeding with Gleevec (150 mg/kg bid) or $\mathrm{H}_{2} \mathrm{O}(200 \mu \mathrm{l})$ and analyzed by flow cytometry using anti-CD3 and anti-NK1.1 mAb's. The absolute numbers of CD3+/NK1.1- T cells and CD3-/NK1.1+ NK cells were deduced from the percentages obtained in 2 independent experiments and are indicated in the boxes (B). T lymphocytes were not activated during Gleevec oral feeding. In the CD3+/ NK1.1- T cell gate, the CD69 expression is shown. (C) NK lymphocytes were activated during therapy with Gleevec. In the CD3-/NK1.1+ NK cell gate, the CD69 expression is shown. Swiss ${ }^{n u / n u}$ mice (D) and C57BL/6 littermates (E) were injected intraperitonealy with $10 \mu \mathrm{g}$ of FL or $100 \mu \mathrm{l}$ of PBS each day for 10 days. From day 7 to day 10, mice received either Gleevec (150 mg/kg bid) or $\mathrm{H}_{2} \mathrm{O}(200 \mu \mathrm{l})$. At day 11 , all mice were sacrificed to analyze the expression of the NK activation marker CD69 on NK1.1+ or DX5 $/$ CD3 ${ }^{-}$splenocytes. Positive controls included mice treated with rhulL-2 $\left(1 \times 10^{5} \mathrm{IU}\right.$ intraperitoneally, bid for 4 days). Groups were compared by analysis of variance (ANOVA) using the nonparametric Kruskall-Wallis test. ${ }^{*} P<0.05$ as compared to PBS. ${ }^{*} P<0.05$ as compared to Gleevec. ${ }^{\dagger} P<0.05$ as compared to FL.

To confirm that DCs were among the pharmacological targets of Gleevec in vivo, we purified splenic CD $11 \mathrm{c}^{+} \mathrm{DCs}$ from Gleevectreated mice and cultured them with NK cells. Long-term treatment with Gleevec markedly enhanced the NK cell stimulatory capacities of splenic CD11c $c^{+}$DCs (Figure 4E). We also investigated the role of Gleevec in the differentiation and activation of CD $11 \mathrm{c}^{+}$DCs in nude mice treated with FL. FL was administered on a daily basis for 10 days, and Gleevec was given orally from day 7 to day 10. Spleens were harvested at day 13, allowing enumeration of $\mathrm{CD} 11 \mathrm{c}^{+} / \mathrm{CD} 11 \mathrm{~b}^{-}$and $\mathrm{CD} 11 \mathrm{c}^{+} / \mathrm{CD} 11 \mathrm{~b}^{+} \mathrm{DC}$ subsets in flow cytometry. As shown in Table 1, there were significantly more DCs in mice that received the combination of FL and Gleevec than in littermates receiving FL alone. Both DC subsets $-\mathrm{CD} 11 \mathrm{c}^{+}$/ $\mathrm{CD}_{11} \mathrm{~b}^{-}$and $\mathrm{CD} 11 \mathrm{c}^{+} / \mathrm{CD} 11 \mathrm{~b}^{+}$- were increased after therapy with FL combined with Gleevec. However, the levels of MHC class II and costimulatory molecules were comparable in both groups, suggesting that Gleevec did not promote DC maturation in vivo and that the NK cell activation observed in vivo was not triggered by the maturation of CD $11 c^{+}$DCs in mice. Gleevec also triggered DC-mediated NK cell activation in the human system as measured by the enhanced lysis of $\mathrm{K} 562$ cells by $\mathrm{CD} 56^{+} / \mathrm{CD}^{-}$peripheral blood NK cells cocultured with human DCs derived from CD34 ${ }^{+}$ precursors and pretreated with Gleevec (Figure 4F). Importantly, Gleevec did not trigger DC maturation in vitro, as assessed by FACS analysis and mixed T lymphocyte reactions (Supplemental Figure 2). Thus, Gleevec selectively promoted the capacity of DCs to stimulate NK cells, but not T cells.. Thus, Gleevec alone or combined with FL promoted NK cell activation in vivo, leading to NK cell-dependent antitumor effects. Host DCs were pharmacological targets of Gleevec and acquired NK cell stimulatory capacity in vitro and in vivo.

KIT signaling in DCs inhibits NK cell activation. We next addressed the involvement of the KIT-dependent transduction pathway in the DC-mediated NK cell activation promoted by Gleevec. Indeed, KIT is expressed on BM-DCs from day 4 to day 6 of the in vitro culture in GM-CSF and IL-4, as well as on CD $11 \mathrm{c}^{+}$DCs in vivo (Supplemental Figure 3, A and B). Therefore, we compared the NK cell functions of KIT-deficient (WBB6F1 Kit ${ }^{\mathrm{W}} / \mathrm{Kit}^{\mathrm{W}-\mathrm{v}}$; W/Wv) mice with those of wild-type WBB6F1 $1^{+/+}$(WT) control mice following stimulation with BM-DCs in vitro or with $\mathrm{FL}+$ Gleevec in vivo. The $\mathrm{W}-\mathrm{v}$ mutant receptor exhibits a point mutation at position 660 of the c-kit sequence $(17,18)$, thereby reducing its kinase 
A

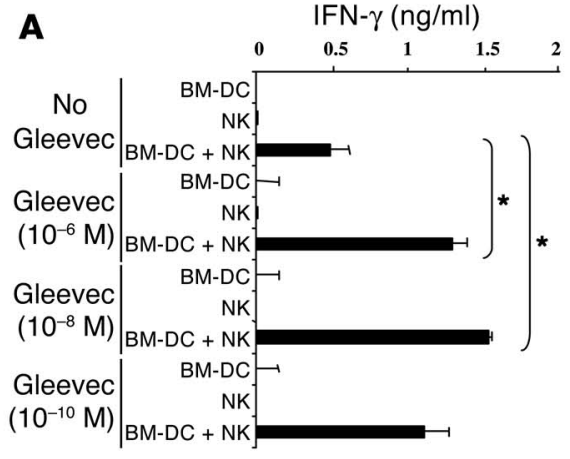

B

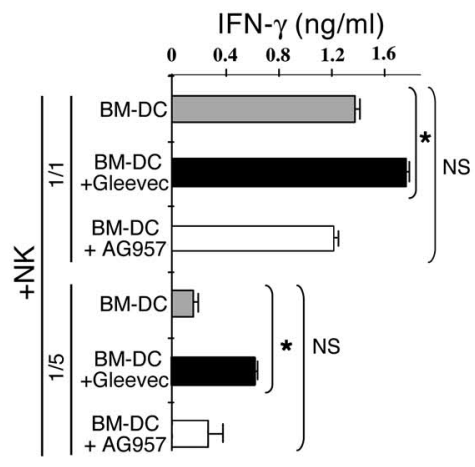

C (1)
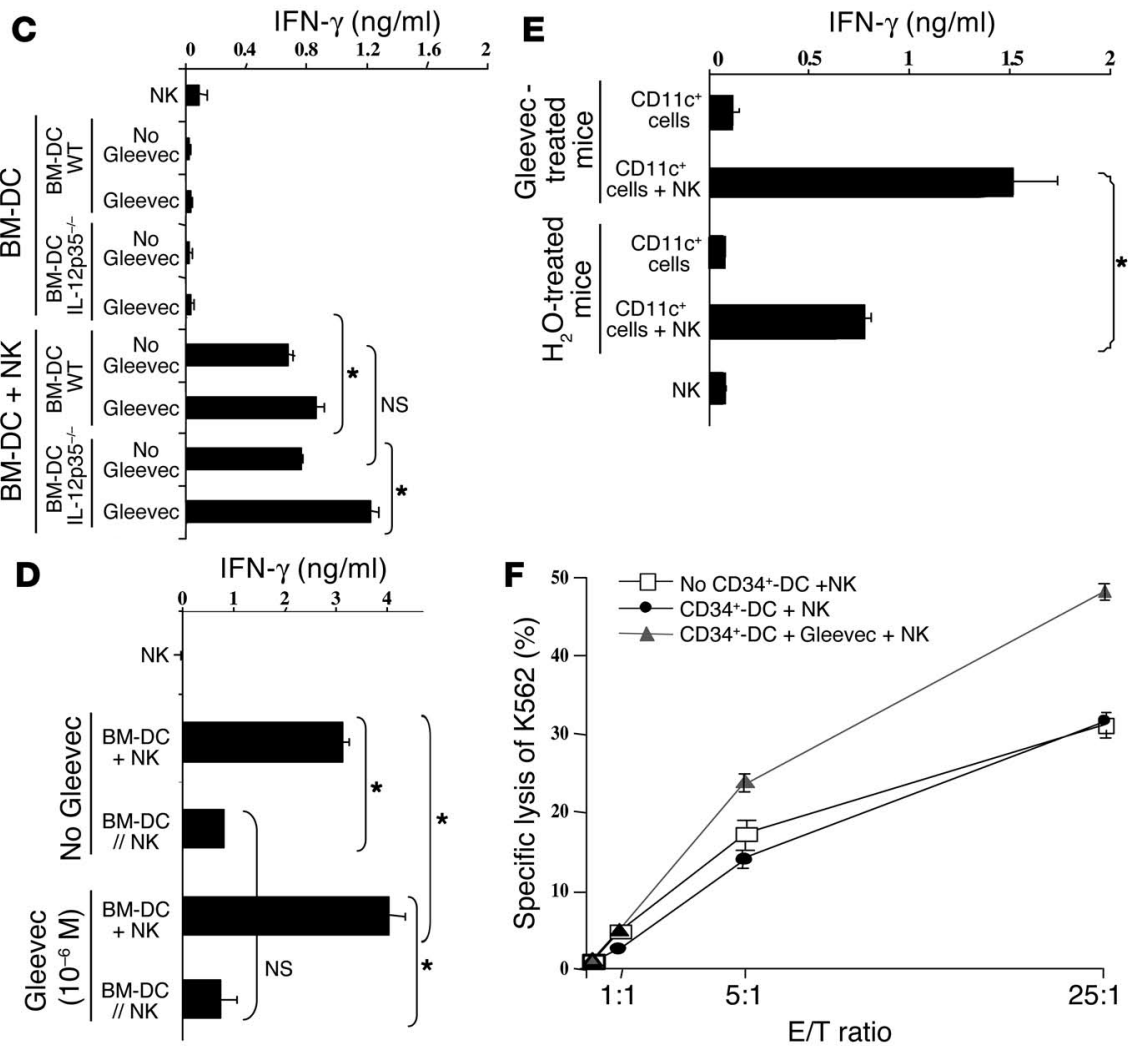

Figure 4

Gleevec endowed DCs with NK cell stimulatory capacity. (A) Mouse DCs pretreated with Gleevec exhibited enhanced NK cell stimulatory capacity in vitro. BM-DC+NK coculture supernatants were monitored for IFN- $\gamma$ secretion. Gleevec alone or FL+Gleevec did not trigger NK cell cytotoxicity or IFN- $\gamma$ production in the absence of BM-DCs. (B) Gleevec but not tyrphostin (AG957) enhanced the NK stimulatory activity of DCs. Experiments were conducted in triplicate at various DC/NK ratios $(1: 2,1: 10)$ in the presence of Gleevec or tyrphostin. (C) IL-12 is not involved in the Gleevec-mediated NK cell activation. Conventions as in A but using IL-12p35 loss-of-function BM-DCs instead of WT BM-DCs. (D) STI-mediated NK cell activation depends on cell-cell contact. BM-DC and NK cell cocultures were separated or not by a trans-well membrane (BM-DC

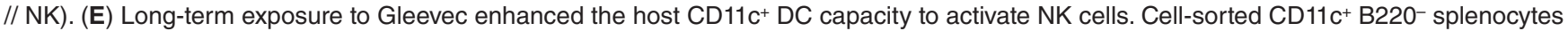
from C57BL/6 mice treated either with $\mathrm{H}_{2} \mathrm{O}$ or Gleevec for 15-21 days were incubated for 20 hours with NK cells as in A. IFN- $\gamma$ release was measured. One representative experiment (out of 2) is shown. (F) Human CD34+-derived DCs stimulated with Gleevec also promoted NK cell activation. After coculture of CD34+-derived DCs with purified human NK cells, NK cell cytolytic activity was observed against K562. Means of triplicate wells are represented (standard errors were consistently less than $10 \%$ of means). One representative experiment (out of 5) is depicted. Groups were compared by ANOVA using the nonparametric Kruskall-Wallis test $\left({ }^{*} P<0.05\right)$.

activity to roughly $10 \%$ of wild-type levels. BM-DCs from $\mathrm{W} / \mathrm{Wv}$ mice displayed the typical phenotypic profile of fully differentiated BM-DCs (Supplemental Figure 4), but were more efficient than WT BM-DCs in activating allogeneic NK cells, but not T cells (not shown) with regard to their ability to trigger NK cell lysis of YAC-1 (Figure 5A) and IFN- $\gamma$ production (Figure 5B). Importantly, Gleevec failed to further enhance the capacity of W/Wv BM-DCs to promote NK cell activation (Figure 5), which is in line with the fact that the pharmacological target of Gleevec was already inhibited. In vivo administration of FL alone (without Gleevec) was able to trigger upregulation of CD69 on W/Wv NK cells (and IFN- $\gamma$ secretion in splenocytes stimulated ex vivo with IL-2; not shown), while the combination of both FL and Gleevec was required to activate NK cells in WT control mice (Figure 5C). This further supports the notion that Gleevec has to act on KIT to induce the DC-mediated NK cell activation. In other words, the treatment with Gleevec provides a phenocopy of the $\mathrm{W} / \mathrm{Wv}$ mutation. Of note, the enhanced NK cell activity observed in W/Wv mice following administration of FL could not be accounted for by the absolute numbers of NK cells or by the mutation itself. Indeed, FL did not augment the absolute numbers of $\mathrm{NK}$ cells in $\mathrm{W} / \mathrm{Wv}$ mice $\left(6.8 \pm 0.4 \times 10^{6}\right.$ in WT versus $5.6 \pm 1.3 \times 10^{6} \mathrm{in} \mathrm{W} / \mathrm{Wv}$ ) as expected from previous reports (13). Moreover, the NK cell activity of $\mathrm{c}-\mathrm{kit}^{-/}$- NK cells from NK-deficient mice (RAG2/ $\mathrm{\gamma c}^{-/-}$) reconstituted with fetal liver hematopoietic stem cells of W/Wv mice was poorly cytolytic (13). All these data indicate that Gleevec stimulates DC-mediated NK cell activity via a direct action on KIT expressed in DCs.

NK cell activation in GIST patients treated with Gleevec. Intrigued by these findings, we wondered whether Gleevec might mediate part of its therapeutic effects on GIST patients through NK cells. To test this hypothesis, we assessed NK cell functions in 49 GIST patients, a fraction of whom were receiving oral therapy with Gleevec (Supplemental Table 1B). To evaluate the NK cell-activation status, we took advantage of an assay in which activated NK cells cocultured with immature allogeneic DCs in the presence of LPS produce IFN- $\gamma(15,19)$. In these conditions, IFN- $\gamma$ was produced in the circulating $\mathrm{CD}^{-} / \mathrm{CD}^{2} 6^{+} \mathrm{NK}$ cells from 24 out of 49 (49\%) GIST patients treated with Gleevec. In contrast, only $21 \%$ 


\section{Table 1}

The combination of FL and Gleevec enhanced differentiation or survival of CD11C+ DC in vivo

$\begin{array}{lcccc} & & & & \\ & \text { PBS } & \text { PBS+Gleevec } & \text { FL } & \text { FL + Gleevec } \\ \text { CD11c } & 6.8 \pm 5.8 & 6.6 \pm 5.8 & 50 \pm 7.5 & 68 \pm 5^{\mathrm{A}} \\ \text { CD11C }^{+} \text {CD11b- } & 3.1 \pm 0.5 & 3.2 \pm 0.5 & 15.3 \pm 4 & 28.2 \pm 2.9^{A} \\ \text { CD11C }^{+} \text {CD11b }^{+} & 3.6 \pm 0.4 & 3.4 \pm 0.4 & 34.8 \pm 6.5 & 40.1 \pm 4.6^{\mathrm{A}}\end{array}$

FL was administered on a daily basis for 10 days in Swiss ${ }^{\text {nu/nu }}$ mice, and Gleevec was given orally from day 7 to day 10 . Spleens were harvested at day 13 allowing enumeration in a trypan blue exclusion assay and in 4 color flow-cytometry analyses of CD11 $\mathrm{c}^{+} / \mathrm{CD}_{11 \mathrm{~b}^{-}}$and $\mathrm{CD} 11 \mathrm{c}^{+} / \mathrm{CD} 11 \mathrm{~b}^{+}$ DC subsets. Both subsets were increased by the combination of FL and Gleevec ( ${ }^{\mathrm{A} P}<0.05$ comparing FL with FL+Gleevec, Student's $t$ test).

of untreated GIST or $11 \%$ of normal volunteers manifested signs of activation (Figure 6A). Of note, a longitudinal study revealed that Gleevec increased NK cell activation when data before and after treatment were compared in 9 out of 11 patients (Figure 6A, linked spots). More importantly, Gleevec-mediated NK cell activation correlated with clinical outcome. None of the patients who displayed enhanced NK cell functions exhibited progressive disease, while all 10 patients with Gleevec refractory GIST continued to manifest poor NK cell activity $(P<0.05$, Figure $6 \mathrm{~B})$. We next studied the time to progression for 43 patients who benefited from a median follow-up of 13.2 months in both cohorts of GIST patients - those who exhibited enhanced NK cell function (22 out of 43) after 2 months of Gleevec and those who did not (21 out of 43). As shown in Figure 6C, the time to progression was significantly longer in patients with NK cell activation (log rank test, $P=0.03$ ). Although prognostic factors influencing the response to Gleevec have not been clearly identified, four factors associated with poor prognosis were recently reported (20): extragastric primary tumor(s); a hemoglobin level of less than $7 \mathrm{~g} / \mathrm{dl}$; performance status over 2; and pulmonary metastases at entry. No significant differences were observed between the two cohorts (Gleevec-

\section{Figure 5}

The c-kit loss-of-function mutation W/Wv conferred a phenotype similar, with regard to DC-mediated NK cell activation, to that found with Gleevec treatment. (A) Deficient KIT signaling enhanced the capacity of DCs to stimulate the cytotoxic activity of NK cells in vitro. The experimental setting was identical to that represented in Figure 4A, except that BM-DCs derived from WT WBB6F1 mice (WT) or from c-kit-deficient WBB6F1 mice (W/Wv) were cocultured with WT NK cells and NK cytotoxicity was assessed on YAC-1 cells (12). (B) Deficient KIT signaling stimulated the capacity of DCs to elicit IFN- $\gamma$ secretion by NK cells in vitro. Instead of measuring the cytotoxic activity as in $\mathbf{A}$, the accumulation of IFN- $\gamma$ in culture supernatants was assessed. (C) The W/Wv mutation allowed FL-mediated NK cell activation in vivo. WT and $\mathrm{W} / \mathrm{Wv}$ mutant mice were treated with $\mathrm{FL}$ in vivo (same doses, schedule, and statistical methods as in Figure 3 ). All experiments were performed 3 times with similar results. ${ }^{*} P<0.05$, significantly different from PBS-treated animals (in W/Wv and WT animals); ${ }^{*} P<0.05$, significantly different from FL-treated animals. responsive versus Gleevec-unnresponsive NK cells) for any of the 4 parameters (69\% vs. $75 \%, P=0.56 ; 12.7$ vs. $12.9 \mathrm{~g} / \mathrm{dl}, P=0.7 ; 7 \%$ vs. $5 \%, P=0.7$; and $5 \%$ vs. $5 \%, P=0.99$, respectively).

To address the clinical relevance of the NK cell activation found after Gleevec administration in GIST patients, we assessed the sensitivity of gastrointestinal stromal tumor cells to NK cell lysis in vitro using a candidate GIST line. This GIST cell line was lysed by IL-2-activated NK cells purified from 7 different GIST-bearing patients at diagnosis. Similar lysis was obtained against the K562 NK cell sensitive target (Figure 7A). We also assessed the cytotoxic functions of freshly purified NK cells from 6 GIST patients, prior to and 2 months after Gleevec therapy (Figure 7B). Gleevec therapy significantly increased NK cell cytotoxicity. The NK cell recognition of GIST and K562 did not differ significantly. We found some molecular features shared by GISTs that could account for their potential NK cell sensitivity in vivo. More than half of the GISTs ( 9 out of $15 ; 60 \%$ ) showed a complete deficiency in the transcription of TAP-1 mRNA, whereas most overexpressed the NKG2D ligands MHC class I-like MICB (4 out of 6), ULBP1 (5 out of 6), and ULBP3 (5 out of 6), compared with nontumoral gut tissue (Supplemental Table 2). These results were confirmed at the protein level by immunohistochemistry on 5 frozen GIST specimens using anti-MHC class I and anti-MICA/B mAb's and by Western blotting (data not shown). The relevance of the DC/NK cell crosstalk leading to NK cell activation in patients has been documented in the skin undergoing severe lichenoid dermatitis. Adverse cutaneous reactions induced by Gleevec are frequent, generally moderate, and dosage dependent (21). The skin was inflamed as

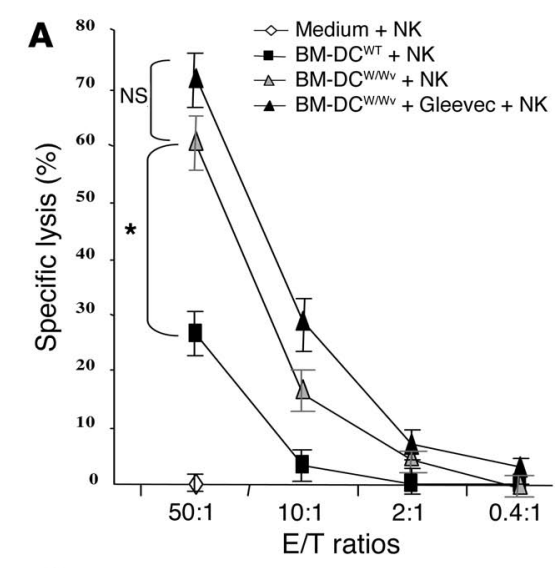

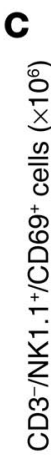

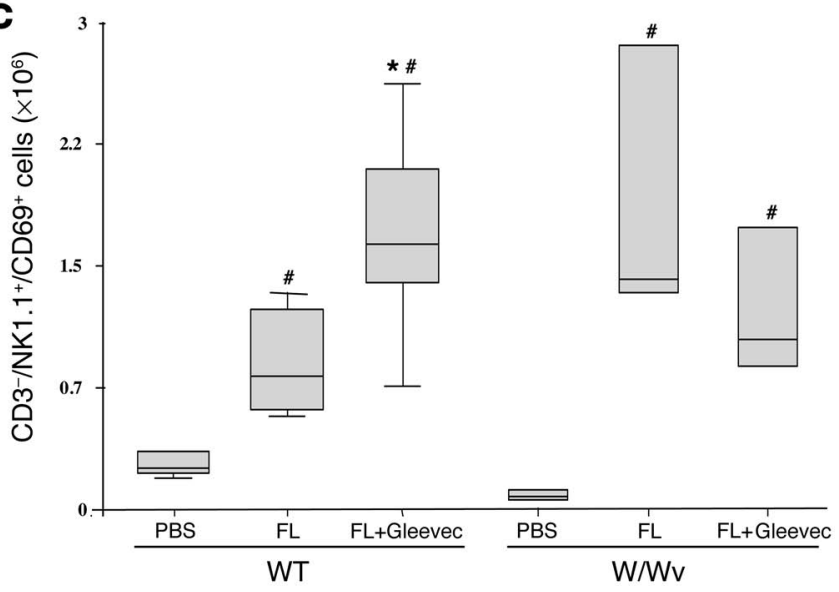




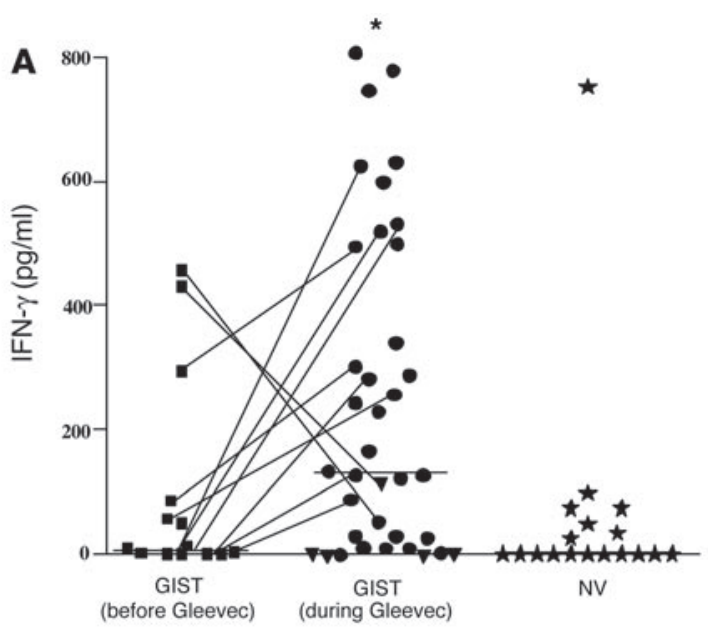

B Correlation between clinical and immunological status of Gleevec-treated patients
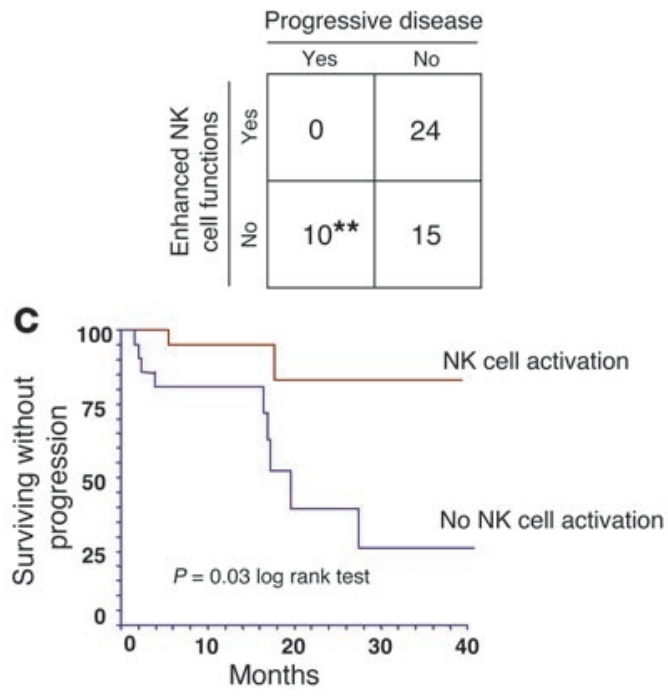

evidenced by the presence of numerous mature DC-LAMP ${ }^{+}$DCs invading the dermis and of $\mathrm{CD} 57^{+} \mathrm{CD} 3^{-} \mathrm{NK}$ cells that eventually interacted (Figure 7B). These images are reminiscent of the DC/ NK cell cross-talk first identified in the atopic dermatitis caused by skin malassezia (22).

\section{Discussion}

Gleevec is a paradigmatic pharmacological agent targeting specific mutations in protooncogenes (KIT/PDGFR/BCR/ABL) that is required for the malignant transformation of stromal cells of the gut (GIST) or myeloid precursors (chronic myeloid leukemia). The clinical breakthrough achieved with Gleevec in the management of irresectable GISTs or progressive chronic myelogenous leukemia $(\mathrm{CML})$ has been approved worldwide $(8,9)$. However, this specific kinase inhibitor appears to promote antitumor effects even in tumors lacking target-activating mutations (Supplemental Table 1A). Here we highlight an alternate mode of action of Gleevec that is not tumor cell-autonomous and that involves host bone marrow-derived DCs. Indeed, we have identified the NK cell-dependent antitumor effects promoted by Gleevec-treated DCs in mouse tumor models; our findings highlight the impor-

\section{Figure 6}

Correlation between NK cell activation and disease control in GIST patients. (A) Therapy with Gleevec-induced enhanced NK cell IFN- $\gamma$ production. Blood NK cells were purified from GIST patients (Supplemental Table 1) at diagnosis after 2-12 months of therapy with 400 $\mathrm{mg}$ of Gleevec or from sex- and age-matched normal volunteers (NV) and cocultured with MD-DCs in the presence of LPS as described in Methods. Filled symbols correspond to individual patients or controls. Circles, objective responses; triangles; progressive disease. A longitudinal study enrolling 11 cases before and after Gleevec treatment is depicted with lines. Asterisk indicates significant differences between mean values of IFN- $\gamma$ production after Gleevec compared with prior Gleevec or controls $(P<0.05)$ in 37 consecutive patients. (B) Correlation between clinical outcome and NK cell activation induced by therapy with Gleevec. The clinical responders exhibited stable disease, or partial or complete regressions (WHO criteria). The biological responders exhibited NK cell IFN- $\gamma$ secretion above $130 \mathrm{pg} / \mathrm{ml}$ after at least 2 months of Gleevec therapy (cut-off defined according to the data shown in A). A significant correlation between NK cell activation and clinical outcome at the time of NK cell activation assessment was found ( ${ }^{\star *} P=0.03$, Fisher's exact method). (C) NK cell activation is associated with prolonged time to progression in GIST patients treated with Gleevec. The study of the time to progression was performed for 43 patients with a median follow-up of 13.2 months. Patients who exhibited enhanced NK cell functions at 2 months of Gleevec $(n=22$; red) and those who did not ( $n=21$; blue) (log rank test, $P=0.03$ ).

tance of Gleevec-mediated NK cell activation in patients bearing GISTs devoid of KIT/PDGFR mutations and displaying clinical responses to Gleevec.

Long-term exposure to Gleevec in mice endows host DCs with enhanced NK cell stimulatory capacity (Figure 4E), and such in vivo effects of Gleevec on host DCs can be dramatically augmented by coadministration of the DC growth factor FL in both NK cell activation (Figure 3, D and E) and NK cell-dependent antitumor activity (Figures 1 and 2). FL led to a marked increase in the frequency of $\mathrm{CD} 11 \mathrm{c}^{+} / \mathrm{KIT}^{+} / \mathrm{CD} 11 \mathrm{~b}^{+} \mathrm{DCs}$, the cell population that presumably responds to Gleevec (Supplemental Figure 3B). In addition, we found that FL could not be substituted for by G-CSF or GM-CSF in association with Gleevec for the expansion of $\mathrm{CD} 9^{+} / \mathrm{DX}^{+} / \mathrm{CD}^{-}$ NK cells in vivo (data not shown). The residual plasmatic concentrations of Gleevec following oral administration of Gleevec at $150 \mathrm{mg} /$ $\mathrm{kg}$ bi-injection daily (bid) were $576 \mathrm{ng} / \mathrm{ml}(1 \mu \mathrm{M})$, corresponding to the $\mathrm{IC}_{50}$ concentration achieved in clinical trials with Gleevec (8). Plasma concentrations of Gleevec peaked at $6,020 \mathrm{ng} / \mathrm{ml}(60 \mu \mathrm{M})$ in $\mathrm{FL}+\mathrm{Gleevec}$, and they peaked at $12,177 \mathrm{ng} / \mathrm{ml}(120 \mu \mathrm{M})$ with Gleevec alone, which supports the hypothesis that DCs are pharmacological targets of Gleevec in vivo.

NK cells have recently been involved in the host-mediated control of cancer. The renaissance of interest in NK cells in tumor immunosurveillance can be attributed to the discovery of stressinduced ligands for receptors that activate NK cells (23-25) and to the relevance of interactions between MHC class I molecules and killer inhibitory receptors in mismatched hematopoietic transplants, which cause NK cell-mediated graft versus leukemia effects (26). Therefore, MHC class I or TAP loss tumor variants and tumors overexpressing NKG2D ligands are ideal targets for NK cell activity (23-29). Here we report that NK cell functions were enhanced in $49 \%$ of Gleevec-treated GIST patients. Our data suggest that Gleevec-mediated NK cell activation might play a part in tumor control either by synergizing with the cell-autonomous effect of Gleevec or by keeping tumors in check after the direct 
action of Gleevec on tumor cells. First, none of the 10 patients who had a progressive disease exhibited enhanced NK cell functions. Importantly, the time to progression was significantly longer in GIST patients for whom Gleevec caused NK cell activation than in patients without NK cell activation. Second, the GIST model bears molecular features of NK cell sensitivity, namely TAP-1 deficiency, loss of MHC class I molecules, high expression of NKG2D ligands (Supplemental Table 2 and data not shown), and GIST recognition by NK cells comparable to that of K562 (Figure 7A). Notably, in $50 \%$ of GIST-bearing patients, a fraction of circulating NK cells showed a downregulation of NKG2D expression at diagnosis (data not shown), which suggests that GISTs secrete soluble NKG2D ligands that might downregulate NKG2D expression on blood NK cells, similarly to the downregulation seen on T cells (30). Nonetheless, the relevance of NKG2D receptors in NK cell recognition of GISTs remains to be established. Moreover, we could not find any modulation of natural killer cytotoxicity receptor (NKp30, 44, 46) expression following Gleevec therapy in circulating NK cells (data not shown). We did not detect circulating IFN- $\gamma$, TNF- $\alpha$, GM-CSF, IL-10, or IL-13 - all cytokines produced mostly by CD56 ${ }^{\text {bright }}$ CD16 NK cells - in any patients, whether or not they showed NK cell activation (data not shown).

The relevance of the DC/NK cell cross-talk is postulated in various physiopathological settings $(22,31-33)$ and has been demonstrated for the control of mouse tumors (10) and the murine cytomegalovirus viral replication in vivo (34). DCs and NK cells might interact in inflammatory lesions where chemokines and cytokines recruit both DCs and NK cells (35) or in the lymph nodes, where cooperation between IL-2-producing $\mathrm{CD}^{+} \mathrm{T}$ cells and NK cells is ongoing (33). Knowledge of whether the Gleevec-conditioned DC/ NK cell cross-talk is mediated in situ or at distant sites (lymphoid organs) remains elusive. Nevertheless, in one patient who benefited from therapy with Gleevec for one year, we found a DC/NK cell interaction in an unusual site (skin undergoing Gleevec-induced lichenoid dermatitis). This side effect regressed after removal of Gleevec, suggesting that the maturation of dermal DCs and/or recruitment of NK cells in the dermis was induced by Gleevec.

Any molecular mechanism accounting for NK cell triggering by Gleevec-stimulated DCs that does not imply the maturation of

\section{Figure 7}

GISTs are NK cell-sensitive targets. (A) NK cell recognition of a GIST cell line. CD3-/CD56+ NK cells from GIST patients at diagnosis were activated overnight with 1000 IU rhulL-2. The cytolytic activity of these NK cells was tested against the NK cell-sensitive K562 targets and against a GIST cell line in a ${ }^{51} \mathrm{Cr}$ release assay, using an $\mathrm{E} / \mathrm{T}$ ratio of 10:1. Data represent the means of triplicate wells of 7 different GIST patients. Each symbol represents an individual patient's NK cell lysis of both targets (see key in B). (B) Gleevec promoted enhanced NK cell recognition of GIST cells. Experimental settings were the same as in $\mathbf{A}$, but cytotoxicity assays had been performed before and 2 months after initiation of Gleevec therapy. (C) DC/NK cell cross-talk in a Gleevecinduced lichenoid dermatitis. Skin biopsies from a lichenoid dermatitis were taken from a patient bearing GISTs in complete regression after a year of oral administration of Gleevec. Formol-fixed and paraffin-embedded sections (4 $\mu \mathrm{m}$ thick) were immunohistochemically stained with an anti-DC-LAMP mAb (Schering-Plough Corp., Dardilly, France) and antiCD57 mAb (NK1, Dako A/S, Glostrup, Denmark). Double-staining with anti-CD3 and anti-CD57 mAb demonstrated that CD57+ cells were all CD3-. DC-LAMP+ mature dendritic cells were visualized by light microscope (brown staining). CD57+ NK cells (3 black boxes) were identified by their red color and visible nuclei ( $\times 400$ magnification).
DCs (see Supplemental Figure 2) or the presence of IL-12 deserves comprehensive analysis. It is worth considering whether adoptive transfer of Gleevec-stimulated DCs or a combination of FL or NK cell-stimulating factors to Gleevec could be suitable therapeutic options in the clinicians' armamentarium against hitherto untreatable NK cell-dependent malignancies or infectious diseases.

\section{Methods}

\section{Patients}

Patients enrolled in the French phase II trial (Institut Gustave Roussy (IGR)/Centre Léon Bérard, Novartis Pharmaceuticals Corp., East Hanover, New Jersey, USA) testing the efficacy of STI571 (imatinib mesylate, Gleevec; formerly called CGP57148; Novartis Pharmaceuticals Corp.). Gleevec in GISTs were studied according to the protocols approved for the follow-up of the patients' immunomonitoring by the local research and ethical committee (Comité Consultatif pour la Protection des Personnes Participant à une Recherche Biomédicale). Peripheral blood $(60 \mathrm{ml})$ was drawn from GIST patients before and 2-6 months after treatment with Gleevec (400 mg/day) for purification of NK cells. Age- and sex-matched normal volunteers were chosen for control studies. Patients' characteristics are described in Supplemental Table 1B. Tumor response was assessed by computed tomography (CT) scan with response classified according to WHO criteria at 2 and 12 months after the beginning of treatment. Nonprogressive disease comprised stable disease and objective partial or complete responses.

\section{Mice}

Female C57BL/6 $\left(\mathrm{H}-2^{\mathrm{b}}\right)$ wild-type or Rag2 $2^{-/-}$mice and female BALB/c SCID $\left(\mathrm{H}-2^{\mathrm{d}}\right)$ mice were obtained from the Center d'Elevage Janvier (Le Genest St. Isle, France) and the Center d' Elevage Iffa Credo (L'Arbresle, France) and maintained in the Animal Facility of Institute Gustave Roussy according to the animal experimental ethics committee guidelines of the facility. Swiss ${ }^{n u / n u}$ mice were maintained at the IGR animal facility. Mast cell-defi-
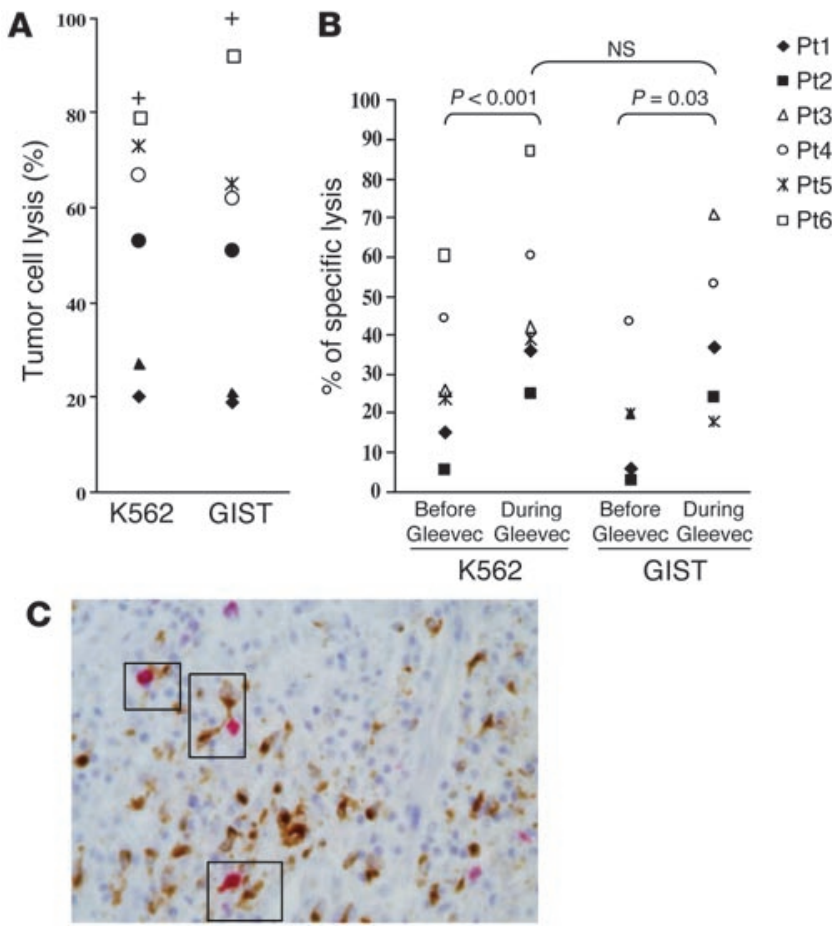
cient $\left(\mathrm{WBB} 6 \mathrm{~F} 1^{\mathrm{W} / \mathrm{WV}}\right)(\mathrm{W} / \mathrm{Wv})$ and control congenic mast cell-sufficient $\left(\mathrm{WBB} 6 \mathrm{~F} 1^{+/+}\right)(\mathrm{WT})$ mice were raised at the Institut Pasteur animal facility (Paris, France). The original stocks of parental strains (i.e., WB-W/+ and C57BL/6- $\mathrm{W}^{\mathrm{v}} /+$ ) were obtained from The Jackson Laboratory (Bar Harbor, Maine, USA). BM mast cells derived from $\mathrm{W} / \mathrm{Wv}$ mice, which lack tissue mast cells due to a point mutation at position 660 of the c-kit sequence $(17,18)$, exhibit markedly reduced phosphorylation of the KIT molecule upon stimulation with stem cell factor (SCF). All female mice were used at 6-25 weeks of age.

\section{Generation of dendritic cells in vitro}

Mouse BM-DCs. BM-DCs were propagated from BM progenitor cells of $\mathrm{WT}$ or $\mathrm{W} / \mathrm{Wv}$ mice in culture medium supplemented with $1,000 \mathrm{IU} / \mathrm{ml}$ of rmGM-CSF (R \& D Systems, Minneapolis, Minnesota, USA) and 1,000 $\mathrm{IU} / \mathrm{ml}$ of rmIL-4 (R \& D Systems) as previously described (12). Culture medium was renewed at days 2 and 4. DCs were harvested on day 5 or 6 , spun down, and transferred into new 6-well plates (referred to as "day 7 DC" henceforth). To modulate BM-DC phenotype, cultures of BM-DCs were incubated in Gleevec $\left(10^{-6} \mathrm{M}, 10^{-8} \mathrm{M}\right.$ or $10^{-10} \mathrm{M}$; neosynthetized by C. Auclair, Institut Gustave Roussy) on day 5 or 6 of culture for 20 hours before use. For phenotypic analyses, cells were incubated with FITC-conjugated anti-I-A $\mathrm{b}^{\mathrm{b}}$ (AF6-120.1) and PE-conjugated anti-CD11c (HL-3); FITCconjugated CD86 (GL1), CD40 (3/23), H-2Kb (AF6-885); and PE-conjugated anti-CD80 (16-10A1), H-2Db (KH95). All antibodies were purchased from BD Biosciences - Pharmingen (San Diego, California, USA). Cells were gated according to size and granulosity with exclusion of propidium iodide-positive cells. Residual B lymphocytes (B220 cells) and granulocytes $\left(\mathrm{Gr} 1^{+}\right.$cells) were detected in the $\mathrm{CD} 11 \mathrm{c}^{-} / \mathrm{I}-\mathrm{A}^{\mathrm{b}-}$ cells and constituted less than $20 \%$ of the total cell population. T cells and NK cells were not propagated in these DC culture conditions. BM-DCs derived from loss-offunction mice (W/Wv) were analyzed for MHC class I expression and exhibited levels of MHC class II, CD80, CD86, and CD40 expression comparable to those of wild-type BM-DCs.

Human CD34+-derived DCs. G-CSF-mobilized human peripheral blood stem cells from normal volunteers or patients were isolated and subjected to sorting of $\mathrm{CD} 34^{+}$progenitors (MACS system, CD34 selection kit; Miltenyi Biotec $\mathrm{GmbH}$, Bergisch-Gladbach, Germany). Half a million cells were propagated in 96-well plates using RPMI1640 (Life Technologies, Cergy Pontoise, France) supplemented with $2 \mathrm{mM}$ L-glutamine, $100 \mathrm{IU} / \mathrm{ml}$ penicillin, $100 \mu \mathrm{g} / \mathrm{ml}$ streptomycin (Life Technologies), 10\% heat-inactivated, endotoxin-free fetal calf serum (PAN Biotech GmbH, Aidenbach, Germany) and a cocktail of cytokines, including SCF $(25 \mathrm{ng} / \mathrm{ml}$; Amgen, Thousand Oaks, California, USA), rhuGM-CSF (1,000 IU/ml, Leucomax, ScheringPlough, Levallois-Perret, France), and rhuTNF- $\alpha$ ( $25 \mathrm{ng} / \mathrm{ml}$, Boehringer Ingelheim $\mathrm{GmbH}$, Mannheim, Germany), herein referred to as complete medium, for 13 days. Complete medium was renewed every 3 or 4 days and cells were expanded at a concentration of $0.5 \times 10^{6} / \mathrm{ml}$. Gleevec was added to culture medium at day 12 for 20 hours before use in NK cell bioassays.

\section{Preparation of NK cells}

Mouse NK cells. Splenocytes were harvested from BL6-Rag2 $/$ - or BALB/c SCID mice. Splenic nonadherent cells were generated by subjecting red blood cell-deprived splenocytes to 3 hours of adherence at $37^{\circ} \mathrm{C}$. Nonadherent cells were analyzed by FACS using monoclonal antibodies to CD3FITC, NK1.1-PE, DX5-PE, or CD69CyC prior to coculture with BM-DCs. Up to $40 \%$ of such splenocytes were CD3-/DX5 $5^{+}$.

Human NK cells. Purified (85-95\% CD56 $\left.{ }^{+} / \mathrm{CD}^{-}\right)$resting NK cells were obtained from peripheral blood lymphocytes from normal volunteers or GIST patients by magnetic cell separation (Miltenyi Biotech) using a two-step protocol: PBMCs were first incubated with hapten-conjugated monoclonal antibodies to CD3, CD14, CD19, CD36, and IgE for 30 minutes followed by negative selection with MACS antihapten microbeads (Miltenyi Biotech).

\section{Preparation of DC/NK cell cocultures}

Procedures have been previously described $(12,19)$. Main principles are described in the figure legends.

Mouse cocultures. Culture medium used was RPMI1640-based complete medium containing $10 \%$ heat-inactivated bovine serum for mouse cultures and RPMI1640 + 10\% heat-inactivated pooled ABS for human cocultures. NK cells (human $\mathrm{CD} 3^{-} / \mathrm{CD}^{2} 6^{+}$or mouse splenocytes from immunodeficient mice) were seeded at $10^{5} /$ well in 96 -well plates for 40 hours (human cocultures) or 20 hours (mouse cocultures). DC/NK ratios of mouse cocultures were 0.5:1.0 (unless otherwise specified) and 1:25 for human cocultures or as specified in figure legends. Mouse BM-DC/NK cocultures were performed in an allogeneic (B6/BALB/c or WBB6F1 ${ }^{\mathrm{W} / \mathrm{Wv}} / \mathrm{BALB} / \mathrm{c}$ or Rag2 $2^{-/}$ BL6, WBB6F1 ${ }^{\mathrm{WT}} / \mathrm{BALB} / \mathrm{c}$ or Rag2-/-BL6) or syngeneic (B6/B6) system.

Human cocultures. Human immature MD-DCs were propagated from normal volunteers' peripheral monocytes in rhGM-CSF $(1,000 \mathrm{IU} / \mathrm{ml})+$ rhIL-4 $(1,000 \mathrm{IU} / \mathrm{ml})$ in AIMV at $3 \times 10^{5}$ cells $/ \mathrm{ml}$ without serum and frozen at day 5 , and subsequently thawed for 2 days in complete medium before coculture with allogeneic NK cells (normal volunteers or GIST patients). FACS analysis showing expression of CD1a, CD11c, and DC-SIGN, low levels of HLA-DR, CD80, and CD40, and lack of expression of CD83 confirmed their immature phenotype. Quality control parameters of MD-DCs included mixed lymphocyte reactions in the presence or absence of LPS. NK cells were cocultured with allogeneic immature DCs for 40 hours in $10 \%$ pooled $\mathrm{AB}$ serum at a ratio of 1:1 in the presence of $1 \mu \mathrm{g} / \mathrm{ml} \mathrm{LPS}(19)$.

\section{Assessment of NK cell effector functions}

Cytotoxicity assays. Cells from 20-hour cocultures were collected. Viable NK cells that were stained with trypan blue (Life Technologies) were counted and used as effector cells. Cytotoxicity of NK cells was measured in a standard 4-hour ${ }^{51} \mathrm{Cr}$-release assay using $\mathrm{Na}_{2}{ }^{51} \mathrm{CrO}_{4}$-labeled $\mathrm{K} 562$ (human cocultures) or YAC-1 targets (mouse cocultures). Experiments were conducted in triplicate at various effector/target $(\mathrm{E} / \mathrm{T})$ ratios. In some experiments, target cells were a GIST cell line provided by J.A. Fletcher.

Cytokine detection and quantification (IFN- $\gamma$ ). After DC/NK coculture, supernatants were harvested, stored at $-80^{\circ} \mathrm{C}$, and then assessed either directly or after 2-10 times dilution using commercial ELISA kits (as noted in figure legends) (BD Biosciences - Pharmingen).

\section{Assessment of in vivo NK cell functions}

C57BL/6 mice or Swiss ${ }^{n u / n u}$ phenotype were subjected to intraperitoneal administration of FL ( $10 \mu \mathrm{g} /$ mouse/day for 10 days) (kindly provided by Immunex Corp., Seattle, Washington, USA) along with oral feeding of PBS or Gleevec ( $150 \mathrm{mg} / \mathrm{kg}$ bid) for the last 4 days. Negative control mice received PBS intraperitoneally and orally only, and positive control mice were injected intraperitoneally with rhIL-2 (Roussel Uclaf, Romainville, France) at $10^{5} \mathrm{IU} /$ mouse, bid for 4 days. Mice were sacrificed at day 11 to examine CD69 expression levels on $\mathrm{DX}^{+} / \mathrm{CD} 3-$ (non-BL6 background) or $\mathrm{NK} 1.1^{+} / \mathrm{CD}^{-} \mathrm{NK}$ cells on splenocytes. Cells were enumerated using trypan blue exclusion prior to immunostaining with three-color mAb's (anti-CD3 FITC, anti-DX5-PE or anti-NK1.1-PE, and anti-CD69CyC).

\section{Tumor models}

RMA is a Rauscher's virus-induced lymphoma cell line derived from B6, and RMA-S is a TAP-defective variant of RMA. One million cells of each tumor line were injected subcutaneously into each flank of C57BL/6 mice, and tumor growth was monitored biweekly in each treatment group. AK7 is an asbestos-induced mesothelioma from $\mathrm{C} 57 \mathrm{BL} / 6$ mice, as previously 
described (12) MCA102 is a methylcholanthrene-induced sarcoma and $\mathrm{B} 16 \mathrm{~F} 10$ is a melanoma; both are from a C57BL/6 background (kindly provided by M.T. Lotze, University of Pittsburgh, Pittsburgh, Pennsylvania, USA). YAC-1 is a Moloney leukemia virus-induced lymphoma cell line from $\mathrm{A} / \mathrm{Sn}(\mathrm{H}-2 \mathrm{a})$ mice.

\section{Statistical analyses}

Results are expressed as means \pm SEM or as ranges when appropriate. Groups were compared by using analysis of variance (ANOVA) followed by multiple comparison of means with Fischer's least-significance procedure. When the variables studied were not normally distributed, nonparametric statistical methods were used. The Wilcoxon two-sample rank sum test was used to compare the values of continuous variables between two groups. When three or more groups were compared, the Kruskall-Wallis test was used. Paired comparisons were made using Wilcoxon's paired test. $P$ values less than 0.05 were considered significant.

\section{Acknowledgments}

$\mathrm{M}$. Terme has received a fellowship from the Ligue Française Contre le Cancer. C. Borg was supported by the Hospices Civils de Lyon and by the Association pour la Recherche Contre le Cancer
(ARC). We are indebted to Novartis Pharmaceuticals Corp. for the authorization given to IGR to assess the NK cell effector functions of patients in the phase II trial. This work has also been supported by INSERM, the ARC and LIGUE Labellisée Française Contre le Cancer, and a European Community Contract 503319 Allostem grant. We are more than grateful to Alain Deroussent, the core facility for mass spectrometry, Institut Fédératif de Recherche 54 , and to the patients who participated. We thank Micheline Hadjard for her incredible devotion in harvesting and collecting patient specimens. We remain indebted to the IGR Animal Facility Staff for technical help.

Received for publication January 16, 2004, and accepted in revised form June 15, 2004.

Address correspondence to: Laurence Zitvogel, ERM0208 INSERM, Department of Clinical Biology, Institut Gustave Roussy, 39 rue Camille Desmoulins, 94805 Villejuif Cedex, France. Phone: 33-142-11-50-41; Fax: 33-1-42-11-60-94; E-mail: zitvogel@igr.fr.

\section{Borg, M. Terme, and J. Taïeb contributed equally to this work.}

1. Rubin, B.P., et al. 2001. KIT activation is a ubiquitous feature of gastrointestinal stromal tumors. Cancer Res. 61:8118-8121.

2. Heinrich, M.C., et al. 2003. PDGFRA activating mutations in gastrointestinal stromal tumors. Science. 31:708-710.

3. Apperley, J.F., et al. 2002. Response to imatinib mesylate in patients with chronic myeloproliferative diseases with rearrangements of the plateletderived growth factor receptor beta. N. Engl.J. Med. 347:481-487.

4. Buchdunger, E., O'Reilly, T., and Wood, J. 2002 Pharmacology of imatinib (STI571). Eur. J. Cancer. 38:S28-S36.

5. Heinrich, M.C., Blanke, C.D., Druker, B.J., and Corless, C.L. 2002. Inhibition of KIT tyrosine kinase activity: a novel molecular approach to the treatment of KIT-positive malignancies. J. Clin. Oncol. 20:1692-1703.

6. Demetri, G.D., et al. 2002. Efficacy and safety of imatinib mesylate in advanced gastrointestinal stromal tumors. N. Engl. J. Med. 347:472-480.

7. Heinrich, M.C., et al. 2003. Kinase mutations and imatinib response in patients with metastatic gastrointestinal stromal tumor. J. Clin. Oncol. 21:4342-4349.

8. Cohen, M.H., et al. 2002. Approval summary for imatinib mesylate capsules in the treatment of chronic myelogenous leukemia. Clin. Cancer. Res. 8:935-942.

9. Bauer, S., et al. 2003. Response to imatinib mesylate of a gastrointestinal stromal tumor with very low expression of KIT. Cancer Chemother. Pharmacol. 51:261-265.

10. Fernandez, N.C., et al. 1999. Dendritic cells (DC) promote natural killer (NK) cell functions: dynamics of the human DC/NK cell cross talk. Nat. Med. 5:405-411.

11. Glas, R., et al. 2000. Recruitment and activation of natural killer (NK) cells in vivo determined by the target cell phenotype. An adaptive component of NK cell-mediated responses. J. Exp. Med. 191:129-138.

12. Seaman, W.E., Sleisenger, M., Eriksson, E., and Koo, G.C. 1987. Depletion of natural killer cells in mice by monoclonal antibody to NK-1.1. Reduc- tion in host defense against malignancy without loss of cellular or humoral immunity. J. Immunol. 138:4539-4544.

13. Colucci, F., and Di Santo, J.P. 2000. The receptor tyrosine kinase c-kit provides a critical signal for survival, expansion, and maturation of mouse natural killer cells. Blood. 95:984-991.

14. Maraskovsky, E., et al. 1996. Dramatic increase in the numbers of functionally mature dendritic cells in Flt3 ligand-treated mice: multiple dendritic cell subpopulations identified. J. Exp. Med. 184:1953-1962.

15. Gerosa, F., et al. 2002. Reciprocal activating interaction between natural killer cells and dendritic cells. J. Exp. Med. 195:327-333.

16. Sun, X., Layton, J.E., Elefanty, A., and Lieschke, G.J. 2001. Comparison of effects of the tyrosine kinase inhibitors AG957, AG490, and STI571 on BCR-ABL-expressing cells, demonstrating synergy between AG490 and STI571. Blood. 97:2008-2015.

17. Nocka, K., et al. 1990. Molecular bases of dominant negative and loss of function mutations at the murine c-kit/white spotting locus: W37, Wv, W41 and W. EMBO J. 9:1805-1813.

18. Kitamura, Y., Matsuda, H., and Hatanaka, K. 1979. Clonal nature of mast-cell clusters formed in $\mathrm{W} / \mathrm{Wv}$ mice after bone marrow transplantation. Nature. 281:154-155.

19. Fernandez, N.C., et al. 2002. Dendritic cells (DC) promote natural killer (NK) cell functions: dynamics of the human DC/NK cell cross talk. Eur. Cytokine Netw. 13:17-27.

20. Van Glabbeke, M.M., et al. 2003. Prognostic factors of toxicity and efficacy in patients with gastro-intestinal stromal tumors (GIST) treated with imatinib: A study of the EORTC-STBSG, ISG and AGITG [abstract]. Proc. Am. Soc. Clin. Oncol. 22:3286.

21. Valeyrie, L., et al. 2003. Adverse cutaneous reactions to imatinib (STI571) in Philadelphia chromosome-positive leukemias: a prospective study of 54 patients. J. Am. Acad. Dermatol. 48:201-206.

22. Buentke, E., et al. 2002. Natural killer and dendritic cell contact in lesional atopic dermatitis skinMalassezia-influenced cell interaction. J. Invest. Dermatol. 119:850-857.

23. Diefenbach, A., Jensen, E.R., Jamieson, A.M., and Raulet, D.H. 2001. Rae1 and H60 ligands of the
NKG2D receptor stimulate tumour immunity. Nature. 413:165-171.

24. Cerwenka, A., Baron, J.L., and Lanier, L.L. 2001. Ectopic expression of retinoic acid early inducible- 1 gene (RAE-1) permits natural killer cell-mediated rejection of a MHC class I-bearing tumor in vivo. Proc. Natl. Acad. Sci. U. S. A. 20:11521-11526.

25. Lanier, L.L. 2001. A renaissance for the tumor immunosurveillance hypothesis. Nat. Med. 11:1178-1180.

26. Ruggeri, L., et al. 2002. Effectiveness of donor natural killer cell alloreactivity in mismatched hematopoietic transplants. Science. 295:2097-2100.

27. Salcedo, M., Momburg, F., Hammerling, G.J., and Ljunggren, H.G. 1994. Resistance to natural killer cell lysis conferred by TAP $1 / 2$ genes in human antigen-processing mutant cells. J. Immunol. 152:1702-1708.

28. Bauer, S., et al. 1999. Activation of NK cells and $\mathrm{T}$ cells by NKG2D, a receptor for stress-inducible MICA. Science. 285:727-729.

29. Cosman, D., et al. 2001. ULBPs, novel MHC class I-related molecules, bind to CMV glycoprotein UL16 and stimulate NK cytotoxicity through the NKG2D receptor. Immunity. 14:123-133.

30. Groh, V., Wu, J., Yee, C., and Spies, T. 2002. Tumourderived soluble MIC ligands impair expression of NKG2D and T-cell activation. Nature. 419:734-738.

31. Moretta, A. 2002. Natural killer cells and dendritic cells: rendezvous in abused tissues. Nat. Rev. Immunol. 2:957-964.

32. Zitvogel, L. 2002. Dendritic and natural killer cells cooperate in the control/switch of innate immunity. J. Exp. Med. 195:F9-F14.

33. Fehniger, T.A., et al. 2003. CD56 $6^{\text {bright }}$ natural killer cells are present in human lymph nodes and are activated by T cell-derived IL-2: a potential new link between adaptive and innate immunity. Blood. 101:3052-3057.

34. Andrews, D.M., Scalzo, A.A., Yokoyama, W.M., Smyth, M.J., and Degli-Esposti, M.A. 2003. Functional interactions between dendritic cells and NK cells during viral infection. Nat. Immunol. 4:175-181.

35. Mantovani, A., Gray, P.A., Van Damme, J., and Sozzani, S. 2000. Macrophage-derived chemokine (MDC). J. Leukoc. Biol. 68:400-404. 